\title{
Musculoskeletal symptoms and job satisfaction among office-workers: A Cross- sectional study from Iran
}

\author{
Amir Loghmani, Parastoo Golshiri, Ahmadreza Zamani, Maryam Kheirmand, \\ Najmeh Jafari
}

Community Medicine Department School of Medicine, Isfahan University of Medical Sciences, Isfahan, Iran

Corresponding author: Ahmadreza Zamani Community Medicine Department, School of Medicine Isfahan University of Medical Sciences, Hezar Jerib St.

Isfahan, Iran zamani@med.mui.ac.ir Tel.: + 983117922542

Fax.: + 983117922542

Received: 11 March 2013

Accepted: 10 May 2013

Copyright (C) 2013 by Academy of Sciences and Arts of Bosnia and Herzegovina. E-mail for permission to publish: amabih@anubih.ba

\begin{abstract}
Objective. Office-work poses a high-risk for musculoskeletal disorders (MSDs), with consequences for workers, employers and society. The aims of this study were to determine the prevalence of musculoskeletal symptoms in a sample of Iranian office workers, to investigate the association between pain severity and job satisfaction and to investigate the association between MSDs and job satisfaction. Materials and methods. Iranian office workers from a university setting $(\mathrm{n}=91)$ were randomly selected and included in this cross-sectional study. The Nordic musculoskeletal questionnaire plus visual analogue scale of pain, and the Brayfield-Rothe Job Satisfaction Index were used to study the prevalence of MSDs, pain intensity and job satisfaction, respectively. Descriptive analysis, Pearson's correlation, and multiple regression analysis were performed for statistical assessment. Results. Eighty-nine percent of participants reported musculoskeletal symptoms during the past 12 months, most commonly in the neck (69.2\%), low back (58.2\%), knees (41.8\%), shoulders (35.2\%), and upper back (34.1\%). There was a significant negative correlation between pain intensity and job satisfaction. Pain intensity, low-back pain in the last week, wrist pain in the past 12 months and shoulder pain were significantly associated with job satisfaction $(\mathrm{p}<0.05)$. Conclusion. This study provides evidence that musculoskeletal symptoms are common in Iranian office workers, associated with low job satisfaction. These findings indicate the need for more attention to MSDs among office workers and designing effective preventive interventions.
\end{abstract}

Key words: Musculoskeletal pain, Occupational health, Job satisfaction.

\section{Introduction}

Musculoskeletal disorders (MSDs) are among the leading causes of occupational health problems, with consequences for workers, employers and society $(1,2)$. These disorders are widespread in different countries with substantial costs and impact on the quality of life (3). Prevalence data have indicated that more than $25 \%$ of the European working population have reported musculoskeletal symptoms (4). In the United States, MSDs represent $40 \%$ of compensated injuries and cause more work absenteeism than any other group of diseases (5). MSDs among office workers are receiving increas- 
ing attention (6). Increased computer usage has been linked to a high prevalence of musculoskeletal symptoms and these disorders can have detrimental effects on workers' health and productivity $(7,8)$. Physical factors such as: repetitive movements, sustained postures, incorrect work positions, and prolonged sitting in incorrect fixed positions, should be considered $(9,10)$. On the other hand psychosocial factors such as: low job satisfaction, high job demands, low job control, and low workplace social support, have been associated with the onset of MSDs among office workers $(11,12)$. These factors may reinforce each other and their effects may be mediated by cultural or societal factors (13).

Studies on work related MSDs in Iran showed a high prevalence of musculoskeletal symptoms in different work settings, such as: automobile factories (14), rubber factories (15), carpet mending operations (16), the petrochemical industry (17) pharmaceutical industries (18) and health care settings $(19,20)$. Office workers are known to be at high risk of MSDs (21). The point prevalence of low back pain was reported as high as $60 \%$ among office workers in an Iranian university setting (22), but there has not been a comprehensive assessment of the prevalence of MSDs at multiple anatomical sites, and its association with job satisfaction in Iranian office workers.

The aims of this study were to determine the prevalence of musculoskeletal symptoms in a sample of Iranian office workers, to investigate the association between pain severity and job satisfaction, and to explore the association between MSDs and job satisfaction.

\section{Material and methods}

This was a cross-sectional study undertaken in the Medical and Pharmacy schools, of the Isfahan University of Medical Sciences, Is- fahan, Iran. The target population were all administrative office-worker employees of these two schools. The inclusion criteria were people who work with computers for at least 3 hours per day, or have sedentary office-work for at least 6 hours per day, in either permanent or contract employment. The exclusion criteria were people who had had any previous illness and/or injuries that may have contributed to MSDs, or who had less than 1 year work experience. With 95\% confidence interval $(\mathrm{p}=0.6, \mathrm{~d}=0.15)$ (20) and considering $10 \%$ attrition, we considered 95 office workers sufficient to examine the prevalence of MSDs and its association with job satisfaction. A cluster sampling was done. The departments of each school were clustered, and the sample was selected randomly according to the size of each cluster.

\section{Tools}

The main variables of this study were musculoskeletal symptoms, pain intensity and job satisfaction, which were measured using these tools:

\section{The Nordic Musculoskeletal Questionnaire}

The self-rating Nordic Musculoskeletal Questionnaire (NMQ) is a standardized questionnaire to assess the prevalence of musculoskeletal symptoms $(23,24)$. The validity and reliability of this questionnaire have been investigated and approved in different studies and several languages, including the Persian language (25).

The first part of the NMQ is a general questionnaire to collect information about the individual (height, weight, age, handedness, hours worked per week, period of time in present occupation, etc.) as well as work absence (one day or more) due to musculoskeletal problems. It has also 40 forcedchoice items identifying areas of the body causing musculoskeletal problems. Comple- 
tion is aided by a body map to indicate nine anatomical sites: neck, shoulders, upper back, elbows, low back, wrist/hands, hips/ thighs, knees and ankles/feet. Respondents were asked if they had had any musculoskeletal trouble in the last 12 months and the last 7 days, which has prevented normal activity at home or away from home (i.e. loss of function).

\section{The Visual Analogue Scale of Pain}

A Visual Analogue Scale (VAS) is a measurement instrument designed to measure a characteristic or attitude that is believed to range across a continuum of values that cannot easily be directly measured. Operationally a VAS is usually a horizontal line, 100 $\mathrm{mm}$ in length, anchored by word descriptors at each end, with no pain at one end (0) and maximum pain (100) at the other. The participant marks on the line the point that they feel represents their current state of pain. The VAS score was determined by measuring in millimeters from the left hand end of the line to the point that the participant marked, converted into a scale of 0 to 10 .

\section{The Job-Satisfaction Questionnaire}

Job satisfaction was assessed using the Brayfield-Rothe Job-Satisfaction Index (BRJSI) (26). Respondents were instructed to indicate the extent of their agreement with each item using a five point Likert type scale from 1 to 5 as follows: $1=$ strongly disagree, $2=$ disagree, $3=$ neither disagree nor agree, $4=$ agree , and $5=$ strongly agree. The scale includes 10 positive and 8 negative statements. A scale is formed by calculating the mean score for all 18 items, ranging from 18-90 and a higher score indicates higher job satisfaction (25). A total score of 18 to 55 is interpreted as low job satisfaction, while 70 and over is represented high job satisfaction (27). Socio-demographic variables [age, gender, marital status, education and work- ing experience] were collected using a selfrated questionnaire.

\section{Statistical analysis}

All descriptive statistics are presented as means and standard deviations for quantitative variables and as relative frequencies and percentages for categorical variables. The BRJSI score is presented as mean with its $95 \%$ confidence interval. Pearson's correlation coefficient was used to measure the strength of the relationship between pain intensity and job satisfaction. Variables achieving bivariate significance were placed into a linear regression model. Multiple regression (stepwise) analysis was applied to assess the association of MSDs with job satisfaction. The stepwise regression analysis produced our regression model from a set of candidate independent variables, by entering and removing variables into our model. This method may build a single final model, although there are often several good models to describe the association. Variables were selected for inclusion in the stepwise regression model based on theoretical importance, as well as significance in bivariate analyses. Considering job satisfaction as the dependent variable, the independent variables were entered in blocks, starting from the background socio-demographic variables (age, gender, education, marital status, working experience and BMI) and followed by the pain intensity and musculoskeletal symptoms in different anatomical regions. The level of significance was set at $\mathrm{P}<0.05$, and all tests were two-tailed. Collinearity diagnostics were performed by means of the variance inflation factor (VIF) for each independent variable entered in the regression equations. A VIF $>10$ was considered as positive multicollinearity (28). The analysis of data was performed by the Statistical Package for Social Sciences (SPSS version 20) for Mac. 


\section{Ethics statement}

The design of the study was approved by the Ethics committee of Vice Chancellor for Research, Isfahan University of Medical Sciences (project no. 391264). All participants received study information and provided written informed consent. Also, the confidentiality of all information was managed carefully by researchers.

\section{Results}

Of the potential 118 participants, 103 participants responded to the questionnaire, giving a response rate of $87 \%$. Of these, 12 were excluded because they did not meet the inclusion criteria of having at least 1 -year work experience $(n=9)$ or had previous musculoskeletal disorder $(n=3)$, leaving 91 who were included in the study. The mean age of all participants was 39.4 years $(\mathrm{SD}=8.43)$ with a range of 25-58 years. Of these participants,

Table1 Demographic characteristics of officeworkers studied $(n=91)$

\begin{tabular}{ll}
\hline Demographic characteristics & Results \\
\hline Age (Mean \pm SD) & $39.42(8.4)$ \\
\hline Working experience (yrs.) (Mean \pm SD) & $13.69(7.2)$ \\
\hline BMI (Mean \pm SD) & $25.21(2.9)$ \\
\hline Gender $(n ; \%)$ & \\
\hline Female & $67(73.6)$ \\
Male & $24(26.4)$ \\
\hline Marital status $(n ; \%)$ & \\
\hline Single & $13(14.3)$ \\
Married & $78(85.7)$ \\
\hline Education $(n ; \%)$ & \\
\hline Diploma & $14(15.4)$ \\
Associate degree & $12(13.2)$ \\
BSc & $36(39.5)$ \\
MSc & $22(24.2)$ \\
PhD & $6(6.6)$ \\
Post-Doc & $1(1.1)$ \\
\hline
\end{tabular}

67 were female $(73.6 \%)$ and 24 participants were male $(26.4 \%)$ with a female to male ratio of $2.79: 1$. About $85 \%$ of the respondents worked full time (32-41 hours per week) (Table 1).

\section{Prevalence of musculoskeletal symptoms}

Eighty-one (89\%) participants reported musculoskeletal symptoms during the previous 12 months. The body regions most commonly affected were: neck (69.2\%), low back $(58.2 \%)$, knee (41.8\%), shoulders (35.2\%), and upper back (34.1\%). Respondents reported symptoms less commonly in the thighs (7.7\%), arms (5.5\%), and palms (4.3\%) (Table 2). Fifty-five (60.4\%) participants reported loss of function, and work absenteeism was reported in $36.3 \%$ of participants during the previous 12 months.

\section{Pain intensity and job satisfaction}

The results of the visual analogue scale showed a median symptom intensity of 5.29. The mean score of job satisfaction was 54.14 (95\% confidence interval: 51.61 to 56.68 ). The majority of office workers belonged to the low (47.3\%) and intermediate level of job satisfaction (47.3\%). The high level of

Table 2 Prevalence rate of reported MSDs in different body regions during the 12 months prior to the study $(\mathrm{n}=91)$

\begin{tabular}{ll}
\hline Body Region & Number (\%) \\
\hline Neck & $63(69.2)$ \\
Shoulders & $32(35.2)$ \\
Elbows & $12(13.2)$ \\
Wrists/hands & $26(28.5)$ \\
Upper back & $31(34.1)$ \\
Lower back & $53(58.2)$ \\
Thighs & $7(7.7)$ \\
Knees & $38(41.8)$ \\
Ankles/feet & $12(13.2)$ \\
\hline
\end{tabular}


job satisfaction was observed in $5.5 \%$ of our participants. Using Pearson's correlation analysis, the pain intensity was negatively correlated with job satisfaction score $(\mathrm{r}=$ $-0.58, \mathrm{p}<0.001)$.

\section{Musculoskeletal symptoms and job satisfaction}

In multiple linear regression analyses, after evaluating the correlations among the independent variables, no multicollinearity problem was detected. Stepwise linear regression was performed on the variables previously listed, to determine association with job satisfaction. Pain intensity had the strongest association with job satisfaction $\left(\mathrm{R}^{2}=0.39\right)$. To determine which musculoskeletal symptoms of the NMQ were most important in determining its association with the job satisfaction score, the job satisfaction was regressed onto the musculoskeletal symptom. Among these symptoms, low back pain in the last week, wrist pain in the previous 12 months and shoulder pain were associated with significantly worse job satisfaction (Table 3 ).

The final model (model 4) indicated that pain intensity, low back pain in the last week, wrist pain in the previous 12 months and shoulder pain were negatively associated with job satisfaction $(\mathrm{p}<0.05)$. This final model explained $61 \%$ of the variance of the job satisfaction. Demographic factors and musculoskeletal pain in other anatomical regions were not found to be significantly associated with job satisfaction in these participants.

\section{Discussion}

This study investigated the prevalence of musculoskeletal symptoms among officeworkers and their association with job satisfaction. In our study, musculoskeletal symptoms were common among office workers in a university setting. Eighty-nine percent of our participants reported musculoskeletal symptoms during the previous 12 months. Loss of function and work absenteeism were

Table 3 Association of musculoskeletal symptoms and pain intensity with job satisfaction

\begin{tabular}{|c|c|c|c|c|}
\hline Model* $^{*}$ & Standardized beta & $\mathrm{p}$-Value & Standard error of the estimate & R square \\
\hline \multicolumn{5}{|l|}{ Model 1} \\
\hline Pain intensity $(\mathrm{VAS})^{* *}$ & -0.63 & $<0.001$ & 9.96 & 0.39 \\
\hline \multicolumn{5}{|l|}{ Model 2} \\
\hline Pain intensity (VAS) & -0.58 & $<0.001$ & 9.59 & 0.48 \\
\hline Low back pain (last 7-days) & -0.32 & 0.003 & - & - \\
\hline \multicolumn{5}{|l|}{ Model 3} \\
\hline Pain intensity (VAS) & -0.57 & $<0.001$ & 9.33 & 0.55 \\
\hline Low back pain (last 7-days) & -0.29 & 0.008 & - & - \\
\hline Wrist pain (last 12-months) & -0.20 & 0.015 & - & - \\
\hline \multicolumn{5}{|l|}{ Model $4^{* * *}$} \\
\hline Pain intensity (VAS) & -0.53 & $<0.01$ & - & - \\
\hline Low back pain (last 7-days) & -0.27 & 0.005 & 9.17 & 0.61 \\
\hline Wrist pain (last 12-months) & -0.17 & 0.005 & - & - \\
\hline Shoulder pain (last 7-days) & -0.16 & 0.028 & - & - \\
\hline
\end{tabular}


reported in more than half the participants. This indicated that the prevalence of musculoskeletal symptoms is higher in the studied population in comparison to international studies (3, 7, 9, 29-31) and Iran (32).

Office workers were most likely to report musculoskeletal symptoms in their neck (69.2\%), low back (58.2\%), knees (41.8\%), and shoulders (35.2\%). This is line with the previous studies indicating the high prevalence of neck pain in office workers and pain in other regions of the body $(33,34)$. Likewise the prevalence of back pain was in the range of $7.4 \%$ to $59.6 \%$ in previous studies $(21,35-40)$ and upper extremity symptoms ranged from 18.6 to $62.7 \%(34,41,42)$. This wide range in different studies may be due to differences in the work settings and/or in the criteria used for ascertainment of symptoms.

MSDs were the main reasons for workrelated consultations in general practice and medical costs $(43,44)$. Furthermore, musculoskeletal symptoms threaten the quality of life $(45,46)$ and job satisfaction of office workers (47).

Most of our participants reported low to medium job satisfaction. Job satisfaction is simply defined as the degree to which people like their jobs (48). Several studies indicated that the extent to which individuals feel satisfied with their work is associated with their physical and mental health $(49,50)$. A metaanalysis of almost 500 studies of job satisfaction, incorporating over 250,000 employees, found statistical correlations between job satisfaction and measures of mental health; and smaller relationships were detected for measures of physical health (51). In our study, pain intensity was significantly correlated with job satisfaction, and our results from the multiple regression analysis indicate that pain intensity, low back pain in the last week, wrist pain in the previous 12 months and shoulder pain were associated with job satisfaction.
However, previous studies indicated the association between low job satisfaction and musculoskeletal symptoms, such as low back pain $(47,52)$. It seems that there may be a bilateral relationship between job satisfaction and physical health. This implies the need for a holistic approach to improving the bio-psycho-social-environmental health of employees. An important aspect of the current study refers to assessing the prevalence of musculoskeletal symptoms in a developing country and its relationship with job satisfaction.

Lower job satisfaction in developing countries has been reported in several studies, which is in line with our findings (53-55). The proposed reasons for lower job satisfaction in developing countries include lack of employment security, poor salaries, benefits, work conditions, promotion and communication, as well as lower control over job, leadership behaviors, job stress, and mental and physical status (56-59). However, there are some issues that should be considered as limitations of this study. Job satisfaction is a multi-dimensional concept. Several factors, such as: mental health, working hours, economical issues, job security, supervisor support, and changes in job control levels, have also been related to individual job satisfaction levels (60) and are not addressed in this study. Furthermore, satisfaction levels can vary markedly between different job features (61). These all bring raise criticism of the concept of job satisfaction and its measurement. However, there is no 'gold standard' indicating the aspects that should be taken into account when job satisfaction is measured (62). Qualitative studies may be helpful to consider all aspects of job satisfaction in future studies.

The target population in our study was from two schools in a medical university. The higher prevalence of musculoskeletal symptoms in this sample may be related to their higher awareness of medical symptoms 
since they were health care workers. Also, the cross-sectional design of this study limits its generalizability, and causation cannot be inferred. More research, particularly longitudinal, is warranted to direct the causation between musculoskeletal symptoms and job satisfaction. Despite these limitations, the current study appears to be unique in that it used standardized measures to quantitatively evaluate the prevalence of musculoskeletal symptoms and its association with job satisfaction among Iranian office workers.

\section{Conclusion}

In conclusion, our study provides evidence that musculoskeletal symptoms are common in Iranian office workers, which may impact negatively on job satisfaction. These findings indicate the need for more attention to MSDs among office workers and designing effective preventive interventions.

Acknowledgements: This manuscript is the first report of the dissertation project numbered 391264, funded by the Research Chancellor of Isfahan University of Medical Sciences. Our profound gratitude and deepest thanks are extended to all of the officeworkers who so graciously agreed to participate in this study in spite of their high workload, and to S.A. Mostafavi PhD, the Dean of School of Pharmacy, Isfahan University of Medical Sciences, for providing us with an excellent atmosphere for accomplishment of this research. We would also like to thank all the staff of Community Medicine Department for their continued support throughout the project.

Authors contributions: Conception and design: AL, PG, AZ; Acquisition, analysis and interpretation of data: AL, NJ; Drafting the article: AL, NJ; Revising it critically for important intellectual content: AL, NJ.

Conflict of interest: The authors declare that they have no conflict of interest.

\section{References}

1. Koytcheva V, Zhekov A, Lazarou G, Riza E. Musculoskeletal Disorders. Promoting Health for Working Women. 2008:137-60.
2. Hadler NM. Occupational musculoskeletal disorders. Philadelphia: Lippincott Williams \& Wilkins; 2005.

3. Punnett L, Wegman DH. Work-related musculoskeletal disorders: the epidemiologic evidence and the debate. J Electromyogr Kinesiol. 2004;14(1):13-23.

4. European Agency for Safety and Health at Work. Work-Related Musculoskeletal Disorders: Back to Work Report. Luxembourg, Belgium: Office for Official Publications of the European Community; 2008.

5. National Research Council and Institute of Medicine. Musculoskeletal disorders and the workplace; low back and upper Extremities. Washington, DC: National Academy Press; 2001.

6. Sillanpää J, Huikko S, Nyberg M, Kivi P, Laippala P, Uitti J. Effect of work with visual display units on musculo-skeletal disorders in the office environment. Occup Med. 2003;53(7):443-51.

7. Ortiz-Hernández L, Tamez-González S, MartínezAlcántara S, Méndez-Ramírez I. Computer use increases the risk of musculoskeletal disorders among newspaper office workers. Arch Med Res. 2003;34(4):331-42.

8. Griffiths KL, Mackey MG, Adamson BJ. The impact of a computerized work environment on professional occupational groups and behavioural and physiological risk factors for musculoskeletal symptoms: a literature review. J Occup Rehabil. 2007;17(4):743-65.

9. Wu S, He L, Li J, Wang J, Wang S. Visual display terminal use increases the prevalence and risk of work-related musculoskeletal disorders among Chinese office workers: a cross-sectional study. J Occup Health. 2012;54(1):34-43.

10. Andersen JH, Fallentin N, Thomsen JF, Mikkelsen S. Risk factors for neck and upper extremity disorders among computers users and the effect of interventions: an overview of systematic reviews. PLoS One. 2011;6(5):e19691.

11. Harcombe H, McBride D, Derrett S, Gray A. Physical and psychosocial risk factors for musculoskeletal disorders in New Zealand nurses, postal workers and office workers. Inj Prev. 2010;16(2):96-100.

12. Habib RR, Frangieh M, Haddad N, Hojeij S, Coggon D. Musculoskeletal pain and psychosocial factors among Lebanese workers. Occup Environ Med. 2011;68:(Suppl 1)A67.

13. Johnston V, Jull G, Souvlis T, Jimmieson N. Interactive effects from self-reported physical and psychosocial factors in the workplace on neck pain 
and disability in female office workers. Ergonomics. 2010;53(4):502-13.

14. Alipour A, Ghaffari M, Shariati B, Jensen I, Vingard E. Occupational neck and shoulder pain among automobile manufacturing workers in Iran. Am J Ind Med. 2008;51(5):372-9.

15. Choobineh A, Tabatabaei SH, Mokhtarzadeh A, Salehi M. Musculoskeletal problems among workers of an Iranian rubber factory. J Occup Health. 2007;49(5):418-23.

16. Choobineh A, Tosian R, Alhamdi Z, Davarzanie M. Ergonomic intervention in carpet mending operation. Appl Ergon. 2004;35(5):493-6.

17. Choobineh A, Sani GP, Rohani MS, Pour MG, Neghab M. Perceived demands and musculoskeletal symptoms among employees of an Iranian petrochemical industry. Int J Ind Ergon. 2009;39(5):766-70.

18. Pourmahabadian M, Akhavan M, Azam K. Investigation of Risk Factors of Work-Related UpperLimb Musculoskeletal Disorders in a Pharmaceutical Industry. Journal of Applied Sciences. 2008;8(7):1262-7.

19. Choobineh A, Movahed M, Tabatabaie SH, Kumashiro M. Perceived demands and musculoskeletal disorders in operating room nurses of Shiraz city hospitals. Ind Health. 2010;48(1):74-84.

20. Marzieh S. Low Back Pain and neck pain in related to poor posture in hospital female personnel of Fateme-zahra Hospital, Najaf-Abad. Journal of Research in Rehabilitation Sciences. 2011;7(3):259-66.

21. Janwantanakul P, Pensri P, Jiamjarasrangsri V, Sinsongsook T. Prevalence of self-reported musculoskeletal symptoms among office workers. Occup Med. 2008;58(6):436-8.

22. Rezaee M, Ghasemi M, Jafari NJ, Izadi M. Low Back Pain and Related Factors among Iranian Office Workers. International Journal of Occupational Hygiene. 2011;3(1):23-8.

23. Kuorinka I, Jonsson B, Kilbom A, Vinterberg H, Biering-Sørensen F, Andersson G, et al. Standardised Nordic questionnaires for the analysis of musculoskeletal symptoms. Appl Ergon. 1987;18(3):233-7.

24. Descatha A, Roquelaure Y, Chastang J-F, Evanoff B, Melchior M, Mariot C, et al. Validity of Nordicstyle questionnaires in the surveillance of upperlimb work-related musculoskeletal disorders. Scandinavian journal of work, environment \& health. 2007;33(1):58.

25. De Barros E, Alexandre NMC. Cross-cultural adaptation of the Nordic musculoskeletal questionnaire. International nursing review. 2003;50(2):101-8.
26. Brayfield AH, Rothe HF. An index of job satisfaction. Journal of applied psychology. 1951;35(5):307.

27. Rezaei A, Rezvanfar A, Akbari M, Hassanshahi H. Job Satisfaction of Agricultural Education Teachers in Yazd Province of Iran. J Agric Sci Technol. 2008;10:431-8.

28. Kleinbaum DG, Kupper LL, Muller KE. Applied regression analysis and other multivariable methods. Belmont, CA: Duxbury Press; 2007.

29. Korhonen T, Ketola R, Toivonen R, Luukkonen R, Häkkänen M, Viikari-Juntura E. Work related and individual predictors for incident neck pain among office employees working with video display units. Occupational and environmental medicine. 2003;60(7):475-82.

30. Cagnie B, Danneels L, Van Tiggelen D, De Loose $\mathrm{V}$, Cambier D. Individual and work related risk factors for neck pain among office workers: a cross sectional study. European Spine Journal. 2007;16(5):679-86.

31. Eltayeb S, Staal JB, Hassan A, De Bie RA. Work related risk factors for neck, shoulder and arms complaints: a cohort study among Dutch computer office workers. Journal of occupational rehabilitation. 2009;19(4):315-22.

32. Choobineh A, Motamedzade M, Kazemi M, Moghimbeigi A, Heidari Pahlavian A. The impact of ergonomics intervention on psychosocial factors and musculoskeletal symptoms among office workers. International Journal of Industrial Ergonomics. 2011;41(6):671-6.

33. Andersen LL, Christensen KB, Holtermann A, Poulsen OM, Sjogaard G, Pedersen MT, et al. Effect of physical exercise interventions on musculoskeletal pain in all body regions among office workers: A one-year randomized controlled trial. Manual therapy. 2010;15(1):100-4.

34. Blangsted AK, Søgaard K, Hansen EA, Hannerz H, Sjøgaard G. One-year randomized controlled trial with different physical-activity programs to reduce musculoskeletal symptoms in the neck and shoulders among office workers. Scandinavian journal of work, environment \& health. 2008:55-65.

35. Bergqvist U, Wolgast E, Nilsson B, Voss M. The influence of VDT work on musculoskeletal disorders. Ergonomics. 1995;38(4):754-62.

36. Faucett J, Rempel D. VDT-related musculoskeletal symptoms: Interactions between work posture and psychosocial work factors. American Journal of Industrial Medicine. 2007;26(5):597-612.

37. Omokhodion F, Sanya A. Risk factors for low back pain among office workers in Ibadan, Southwest Nigeria. Occupational Medicine. 2003;53(4):287-9.

38. Yue P, Liu F, Li L. Neck/shoulder pain and low back pain among school teachers in China, 
prevalence and risk factors. BMC public health. 2012;12(1):789.

39. O'Sullivan D, Cunningham C, Blake C. Low back pain among Irish farmers. Occupational medicine. 2009;59(1):59-61.

40. Guo H-R, Chang Y-C, Yeh W-Y, Chen C-W, Guo YL. Prevalence of musculoskeletal disorder among workers in Taiwan: a nationwide study. Journal of occupational health. 2004;46(1):26-36.

41. Bergqvist U, Wolgast E, Nilsson B, Voss M. Musculoskeletal disorders among visual display terminal workers: individual, ergonomic, and work organizational factors. Ergonomics. 1995;38(4):763-76.

42. Leroux I, Dionne CE, Bourbonnais R, Brisson C. Prevalence of musculoskeletal pain and associated factors in the Quebec working population. International archives of occupational and environmental health. 2005;78(5):379-86.

43. Reiso H, Nygård JF, Brage S, Gulbrandsen P, Tellnes G. Work ability assessed by patients and their GPs in new episodes of sickness certification. Family practice. 2000;17(2):139-44.

44. Weevers H-JA, Van Der Beek AJ, Anema JR, Van Der Wal G, Van Mechelen W. Work-related disease in general practice: a systematic review. Family practice. 2005;22(2):197-204.

45. Morken T, Riise T, Moen B, Bergum O, Hauge SV, Holien $\mathrm{S}$, et al. Frequent musculoskeletal symptoms and reduced health-related quality of life among industrial workers. Occupational Medicine. 2002;52(2):91-8.

46. Sjögren-Rönkä T, Ojanen MT, Leskinen EK, Mustalampi ST, Mälkiä EA. Physical and psychosocial prerequisites of functioning in relation to work ability and general subjective well-being among office workers. Scandinavian journal of work, environment \& health. 2002:184-90.

47. Andersen JH, Haahr JP, Frost P. Risk factors for more severe regional musculoskeletal symptoms: A two-year prospective study of a general working population. Arthritis \& Rheumatism. 2007;56(4):1355-64.

48. Spector PE. Job satisfaction: Application, assessment, causes, and consequences. Thousand Oaks, CA: Sage Publications, Incorporated; 1997.

49. Sousa-Poza A, Sousa-Poza AA. Well-being at work: a cross-national analysis of the levels and determinants of job satisfaction. Journal of Socioeconomics. 2000;29(6):517-38.

50. De Jonge J, Bosma H, Peter R, Siegrist J. Job strain, effort-reward imbalance and employee well-being: a large-scale cross-sectional study. Social Science and Medicine. 2000;50(9):1317-28.
51. Faragher EB, Cass M, Cooper CL. The relationship between job satisfaction and health: a meta-analysis. Occupational and environmental medicine. 2005;62(2):105-12.

52. Hoogendoorn W, Bongers P, De Vet H, Ariens G, Van Mechelen W, Bouter L. High physical work load and low job satisfaction increase the risk of sickness absence due to low back pain: results of a prospective cohort study. Occupational and Environmental Medicine. 2002;59(5):323-8.

53. ur Rehman M, Irum R, Tahir N, Ijaz Z, Noor U, Salma U. The impact of job stress on employee job satisfaction: A study on private colleges of Pakistan. Journal of Business Studies Quarterly. 2012;3(3):50-6.

54. Abdulla J, Djebarni R, Mellahi K. Determinants of job satisfaction in the UAE: A case study of the Dubai police. Personnel review. 2011;40(1):126-46.

55. Li J, Fu H, Hu Y, Shang L, Wu Y, Kristensen TS, et al. Psychosocial work environment and intention to leave the nursing profession: Results from the longitudinal Chinese NEXT study. Scandinavian journal of public health. 2010;38(Suppl 3):69-80.

56. Rad AMM, Yarmohammadian MH. A study of relationship between managers' leadership style and employees' job satisfaction. Leadership in Health Services. 2006;19(2):11-28.

57. Sultana F, Begum B. Measuring the Job Satisfaction of Female Library Professionals Working in the Health Libraries in Dhaka City. Eastern Librarian. 2012;23(1):37-50.

58. Aghdasi S, Kiamanesh AR, Ebrahim AN. Emotional Intelligence and Organizational Commitment: Testing the Mediatory Role of Occupational Stress and Job Satisfaction. Procedia-Social and Behavioral Sciences. 2011;29:1965-76.

59. Aparcana S, Salhofer S. Development of a social impact assessment methodology for recycling systems in low-income countries. The International Journal of Life Cycle Assessment. 2013:1-10.

60. Noblet A, Rodwell J, McWilliams J. The job strain model is enough for managers: no augmentation needed. Journal of managerial psychology. 2001;16(8):635-49.

61. Nazir NA. Perceived Importance of Job Facets and Overall Job Satisfaction of Bank Employees. Indian Journal of Industrial Relations. 1998:479-96.

62. Roelen C, Koopmans P, Groothoff J. Which work factors determine job satisfaction? Work: A Journal of Prevention, Assessment and Rehabilitation. 2008;30(4):433-9. 